20 Schardey HM, Joosten U, Finke U, et al. The prevention of anastomotic leakage after total gastrectomy with local decontamination. A prospective, randomized, doubleblind, placebo-controlled multicenter trial. Ann Surg 1997; 225: $172-180$.

21 Stoutenbeek CP, van Saene HK, Zandstra DF. Prevention of multiple organ failure by selective decontamination of the digestive tract in multiple trauma patients. In: Faist E, Baue AE, Schildberg FW, eds. The Immune Consequences of Trauma, Shock and Sepsis - Mechanisms and Therapeutic Approaches. Lengerich, Pabst Science Publishers, 1996; pp. 1055-1066.

22 Zwaveling JH, Maring JK, Klompmaker IJ, et al. Selective decontamination of the digestive tract to prevent postoperative infection: a randomized placebo-controlled trial in liver transplant patients. Crit Care Med 2002; 30: 1204-1209.

23 van Nieuwenhoven CA, Buskens E, Bergmans DC, van Tiel FH, Ramsay G, Bonten MJ. Oral decontamination is cost-saving in the prevention of ventilator-associated pneumonia in intensive care units. Crit Care Med 2004; 32: 126-130.

24 van Saene HK, Silvestri L, de la Cal MA, Sarginson RE. Selective decontamination of the digestive tract reduces lower airway and bloodstream infection and mortality and prevents emergence of antimicrobial resistance. Microbes Infect 2006; 8: 953-954.

\title{
Comparisons between portable and chemoluminescence exhaled nitric oxide measurements
}

\section{To the Editors:}

Exhaled nitric oxide fraction ( $F$ eNO), a well-established marker of eosinophilic airway inflammation is elevated in asthma [1, 2]. A recent study showed that changes in FeNO are correlated with changes in asthma control over time in unselected patients [3]. It was also shown that monitoring FeNO enables anti-inflammatory treatment to be tailored more efficiently, thereby resulting in the reduction of inhaled corticosteroid doses without compromising asthma control [4]. Although a more recent study may slightly temper this enthusiasm [5], all these data suggest that FeNO measurement may be helpful in day-to-day asthma management and should, therefore, be integrated into routine testing procedures. So far, however, FeNO has been measured mostly with chemoluminescence equipment that is expensive and bulky, thereby restricting its use in specialised centres. Cheaper handheld devices (NIOX MINO; Aerocrine AB, Solna, Sweden) using an electrochemical sensor to measure FeNO are now available [6] and should allow widespread use of FeNO evaluation in asthma management. The few existing studies that have investigated FeNO measurements achieved with NIOX MINO suggest that FeNO is well correlated (albeit slightly higher) with FeNO measured using the larger chemoluminescence analyser provided by the same manufacturer (Aerocrine AB) [7-9].

In a comparative study, we used both NIOX MINO and a daily calibrated LR-2000 chemoluminescence analyser (Logan Research Ltd, Rochester, UK) to measure FeNO in 102 subjects, including 58 asthma patients (43 patients were treated with inhaled steroids) and 44 nonasthmatic control subjects. Our results confirm that FeNO measured by using NIOX MINO in accordance with manufacturer's instructions is highly correlated $(r=0.957, p<0.001)$ but consistently higher $(p<0.001$ by paired t-test on log-transformed FeNO) than FeNO measured by using our chemoluminescence analyser in accordance with the American Thoracic Society/European Respiratory Society guidelines. A Bland-Altman plot of log transformed FeNO (fig. 1) shows a mean difference equal to 0.144 corresponding to a mean ratio of 1.39 between NIOX MINO and our chemoluminescence analyser (39\% difference). This did not prevent FeNO measurements, obtained with the two devices, to be similarly reliable in discriminating asthma patients from nonasthma subjects (i.e. similar area under the curve on the receiver operating characteristic curve analysis; data not shown). However the optimal FeNO cut-off points that

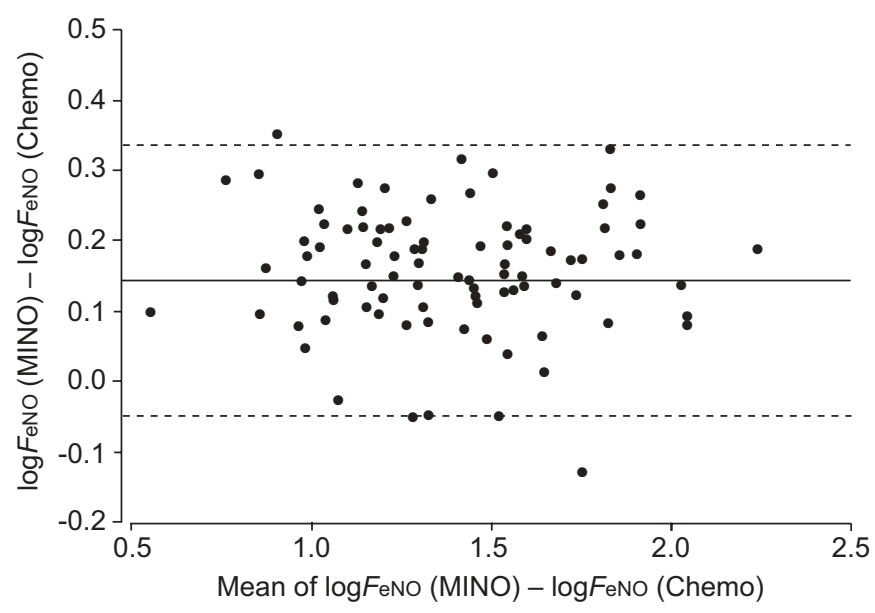

FIGURE 1. Bland--Altman plot comparing log transformed exhaled nitric oxide fraction ( $F$ eNO) from NIOX MINO (MINO; Aerocrine $A B$ ) and chemoluminescence (Chemo) devices. —: mean difference; ----: $\pm 2 \times \mathrm{SD}$. 
emerged from the analysis were clearly different: 43 and $35 \mathrm{ppb}$ for the MINO and Logan devices, respectively.

The methodology used in the two devices is different but this is unlikely to explain the differences reported in this study. Indeed, no difference was detected when samples of known NO concentrations ranging $5-100 \mathrm{ppb}$ and ambient air were analysed with both devices ( $\mathrm{p}=0.18$ by paired $\mathrm{t}$-test). Therefore, differences in expiratory manoeuvres were considered. A micro-spirometer connected to the NIOX MINO showed that the expiratory flow achieved, when patients do expire according to manufacturer's recommendations, is identical to that selected on the chemoluminescence analyser (i.e. $50 \mathrm{~mL} \cdot \mathrm{s}^{-1}$ ). In contrast, the mouth pressures generated during the expiratory manoeuvre, when using the two devices, are notably different; $5 \mathrm{cmH}_{2} \mathrm{O} \quad(0.5 \mathrm{kPa})$ is strictly imposed by our chemoluminescence analyser while a range of pressures between 10 and $20 \mathrm{cmH}_{2} \mathrm{O}(0.98$ to $1.96 \mathrm{kPa})$ is allowed with the MINO device. KONDO et al. [10] showed previously that increased expiratory pressures result in increased FeNO levels determined at a flow rate of $50 \mathrm{~mL} \cdot \mathrm{s}^{-1}$ with a chemoluminescence analyser. In order to test this hypothesis, we measured FeNO in 18 subjects (nine control subjects and nine asthma patients) with the chemoluminescence analyser, before and after a change in the circuit resistance that resulted in the generation of a $15 \mathrm{cmH}_{2} \mathrm{O}(1.5 \mathrm{kPa})$ expiratory pressure during the procedure; a $24.6 \pm 17.4 \%$ increase of FeNO levels occurred when the expiratory pressure increased from 5 to $15 \mathrm{cmH}_{2} \mathrm{O}$ (0.5 to $1.5 \mathrm{kPa}$; $\mathrm{p}<0.001$ by paired t-test). Differences in expiratory pressure, therefore, explain a significant part of the difference we observed in FeNO levels measured with the two devices, the remaining part being in agreement with that found in the previously mentioned studies [7-9].

In conclusion, exhaled nitric oxide fraction measured by the handheld device (NIOX MINO) is strongly correlated with, but consistently higher than, exhaled nitric oxide fraction measured by a chemoluminescence analyser that imposes a lower exhalation pressure. This suggests that monitoring exhalation pressure might be important when repeating and comparing exhaled nitric oxide fraction measurements in asthma patients.

A. Michils*, R. Peché ${ }^{\#}$, S. Baldassarre*, Z. Mourid* and A. Van Muylem*

${ }^{*}$ Chest Dept, CUB Erasme, Brussels, and ${ }^{\#}$ Chest Dept, CHU André Vésale, Montigny-le-Tilleul, Belgium.

\section{STATEMENT OF INTEREST}

A statement of interest for this study can be found at www.erj.ersjournals.com/misc/statements.shtml

\section{ACKNOWLEDGEMENTS}

The authors would like to thank D. Young (Young and Associates, London, UK) for assistance.

\section{REFERENCES}

1 Alving K, Weitzberg E, Lundberg JM. Increased amount of nitric oxide in exhaled air of asthmatics. Eur Respir J 1993; 6: 1368-1370.

2 Kharitonov SA, Yates D, Robbins RA, Logan-Sinclair R, Shinebourne EA, Barnes PJ. Increased nitric oxide in exhaled air of asthmatic patients. Lancet 1994; 343: 133-135.

3 Michils A, Baldassarre S, Van Muylem A. Exhaled nitric oxide and asthma control: a longitudinal study in unselected patients. Eur Respir J 2008; 31; 539-549.

4 Smith AD, Cowan JO, Brassett KP, Herbison GP, Taylor DR. Use of exhaled nitric oxide measurements to guide treatment in chronic asthma. N Engl J Med 2005; 352: 2163-2173.

5 Shaw DE, Berry MA, Thomas M, et al. The use of exhaled nitric oxide to guide asthma management: a randomized controlled trial. Am J Respir Crit Care Med 2007; 176: 231-237.

6 Hemmingsson T, Linnarsson D, Gambert R. Novel handheld device for exhaled nitric oxide-analysis in research and clinical applications. J Clin Monit Comput 2004; 18: 379-387.

7 Alving K, Janson C, Nordvall L. Performance of a new hand-held device for exhaled nitric oxide measurement in adults and children. Respir Res 2006; 7: 67.

8 Vahlkvist S, Sinding M, Skamstrup K, Bisgaard H. Daily home measurements of exhaled nitric oxide in asthmatic children during natural birch pollen exposure. J Allergy Clin Immunol 2006; 117: 1272-1276.

9 Menzies D, Nair A, Lipworth BJ. Portable exhaled nitric oxide measurement: comparison with the "gold standard" technique. Chest 2007; 131: 410-414.

10 Kondo R, Haniuda M, Yamanda $\mathrm{T}$, et al. Effects of expiratory pressure on nitric oxide in exhaled breath. Is exhaled nitric oxide really unaffected by pressure? Respir Physiol Neurobiol 2003; 139: 33-40.

DOI: 10.1183/09031936.00025308

\section{Tacrolimus for antisynthetase syndrome with interstitial lung disease?}

\section{To the Editors:}

We read with great interest the recent case study by GUGLIELMI et al. [1]. They described the clinical course of a 52-yr-old male admitted to hospital for life-threatening acute respiratory distress syndrome (ARDS) and diagnosed with anti-Jo-1 antibody positive polymyositis (antisynthetase syndrome). Improvement and recovery were mainly attributed to institution of immunomodulatory therapy with tacrolimus.

Polymyositis patients with anti-Jo-1 antibodies are generally responsive to corticosteroids [2]. The patient's condition 